\title{
EARLY RESULTS OF TRANSFORAMINAL PERCUTANEOUS ENDOSCOPIC LUMBAR DISCECTOMY UNDER LOCALAND SEDOANALGESIA
}

\author{
(D) Hüseyin Yener ERKEN
}

\author{
Çanakkale Onsekiz Mart University Faculty of Medicine, Department of Orthopedics and Traumatology, Çanakkale, Turkey
}

\begin{abstract}
Objective: After the first description of percutaneous posterolateral nucleotomy by Kambin in 1973, transforaminal percutaneous endoscopic lumbar discectomy (PELD) was developed and its use has been increasing in recent years. To describe the surgical technique and anesthesia protocol of transforaminal PELD under local and sedoanelgesia in patients with lumbar disc herniations (LDH) and to report our early results. Materials and Methods: We included 20 patients who underwent transforaminal PELD under local and sedoanalgesia within a period of two months between January 2019 and February 2019 and who had at least a three-month postoperative follow-up period. LDH was at L4-5 in 28.6\% of the patients, at L5-S1 in 33.3\% of the patients, at L3-4 in 14.3\% of the patients, both at L4-L5 and L5-S1 levels in 14.3\% of the patients, and at L2-L3 in 1 patient.

Results: The mean preoperative Visual anolog scale (VAS) score was $9.4 \pm 1.8$ (range=8-10) and the mean early postoperative VAS score was $1.85 \pm 1.2$ (range=0-6). During follow-up, recurrent LDH was seen in 2 patients. One patient developed epidural fibrosis. The mean VAS scores were found to be $1.8 \pm 1.69$ at the third month follow-up. There was a significant difference between the preoperative VAS scores and the VAS scores in the early postoperative and third month follow-up $(p<0.001)$.

Conclusion: Transforaminal PELD under local and sedoanalgesia is an alternative method to classical microdiscectomy in patients with LDH. It is a crucial advantage that it does not require general anesthesia and that patients can provide feedback during surgery.

Keywords: Percutaneous, endoscopic, lumbar, discectomy, transforaminal, percutaneous endoscopic lumbar discectomy Level of Evidence: Retrospective clinical study, Level III
\end{abstract}

\section{INTRODUCTION}

After the first description of percutaneous posterolateral nucleotomy by Kambin in 1973, transforaminal percutaneous endoscopic lumbar discectomy (PELD) was developed and its use has been increasing in recent years. The transforaminal approach has many advantages over open surgery. These have been described in the literature as the preservation of posterior ligamenteous and bone structures, lesser postoperative instability, facet arthropathy, narrowing of the disc space, and epidural scarring ${ }^{(4,6,13-18,23,30,31,33,34,36,38-42)}$. Migrated discherniations, especially sequestrated ones, may require excessive resection of the lamina when approached by conventional posterior laminotomy. This may cause postoperative instability and low back pain. With the recent advancements in endoscopic spine surgery, the indications of PELD have expanded considerably and many transforaminal and interlaminar endoscopic methods have been described for migrated disc herniations which had been previously considered inaccessible by endoscopic methods ${ }^{(4,5,20,22)}$. The aim of this study is to describe the surgical technique and sedoanalgesia protocol of PELD under local and sedoanelgesia in patients with lumbar disc herniations (LDH) and to report our early results.

\section{MATERIALS AND METHODS}

Our study was a retrospective clinical study performed according to the principles of the World Medical Association Declaration of Helsinki,"Ethical Principles for Medical Research Involving Human Subjects" (revised in 2013). We retrospectively evaluated 20 patients who underwent PELD within a two-month period between January 2019 and February 2019 and who had an at least a three-month postoperative follow-up period. We did not include patients who underwent interlaminar PELD under general anesthesia. The mean age of the patients was $49.7 \pm 18.9$ years. Of patients, 12 were female and 8 were male. LDH was at L4-5 in $28.6 \%$ of the patients, at L5-S1 in $33.3 \%$ of the patients, at $L 3-4$ in $14.3 \%$ of the patients, both at L4-L5 and $\mathrm{L} 5-\mathrm{S} 1$ levels in $14.3 \%$ of the patients, and at L2-L3 in one patient. Anatomically, $61.9 \%$ of LDH's were paracentral, $19 \%$ were foraminal, $9.5 \%$ were down-migrated paracentral, and one 
was centrally located. Three patients had recurrent LDHs which had been previously treated with open microscopic discectomy. All patients underwent transforaminal PELD under local and sedoanalgesia. In $23.8 \%$ of the patients, foraminoplasty was performed by using hand reamers to reach the extruded disc material. All patients who underwent foraminoplasty had LDH at the L5-S1 level. Foraminoplasty was performed in $50 \%$ of patients with LDH at the L5-S1 level. We evaluated the clinical results using visual analog scale (VAS) for leg pain preoperatively, early postoperatively and at three-month intervals postoperatively.

\section{Statistical Analysis}

Statistical analysis was performed in Windows 22 software (IBM Corp.,Armonk, NY) using the IBM SPSS package (Statistical Package for Social Sciences). We used the Paired t-test to compare preoperative and postoperative VAS scores. The value of $p<0.05$ was considered to be statistically significant.

\section{Surgical Technique}

All patients underwent surgery using the Karl Storz Endoscopy Spine TIP System (Karl Storz SE \& CO Tuttlingen, Germany). All surgeries were performed under local anesthesia and conscious sedation in the prone position. Conscious sedation was achieved with midozolam and fentanyl or a combination of midozolam and remifentanyl. Because patients were under conscious sedation, a continuous feedback was obtained from the patient during surgery to prevent any possible neural injury. Midozolam was administered intravenously at a dose of 0.05 $\mathrm{mg} / \mathrm{kg} 30$ minutes before the surgery. If necessary, the same dose was repeated during surgery. Fentanyl was administered intravenously at a dose of $0.8 \mu \mathrm{g} / \mathrm{kg} 10$ minutes before the surgery. During the painful sections of the procedure, such as insertion of the obturator into the disc, the same dose was administrated not to exceed $200 \mu \mathrm{g}$ in total. Remifentayl was started at a dose of $0.1 \mu \mathrm{g} / \mathrm{kg} / \mathrm{min}$ with continuous infusion and the dose was reduced to half of it after the painful sections of the procedure had been completed. The distance from the midline of the skin entry point which was specific for each patient was calculated using axial magnetic resonance (MR) images before the surgery. By giving the necessary tilts to the fluoroscopy, real anteroposterior (AP) and lateral images of the disc space were taken and straight lines were drawn to reach the disc fragment transforaminally. At the intersection of these two lines, the skin and intramuscular space were infiltrated with $1 \%$ lidocaine which coincided with the distance measured previously from axial MR images. An 18-gauge spinal needle was inserted posterolaterally through the skin under fluoroscopy guidance. According to this technique, the distance of the entry point from the middle line in Turkish patients ranged from 9 to $14 \mathrm{~cm}$ according to the structure of the patient and the level of LDH. The placement of the 18-gauge spinal needle in the correct place considering the placement of the disc fragment constitutes the most important step for the removal of the herniation. In endoscopic discectomy, the disc fragment can be removed only if the surgical instrument is placed in the correct place ${ }^{(21)}$. If the needle is in the medial pedicular line in the AP image and at the level of the posterior vertebra in the lateral image at the same time, it means that the needle is in the ideal position (Figure 1). The location of the nerve roots and the safe triangle of Kambin where the drug will spread in the epidural space are confirmed with the injection of the radiopaque (Figure 2). Epidural block is then made with $5 \mathrm{~mL}$ of $0.5 \%$ lidocaine. If the inside-out technique is used, the needle is advanced into the disc and discography is performed with $2 \mathrm{~mL}$ radiopaque to confirm that the needle is in the disc space. Then a $0.8 \mathrm{~mm}$ guidewire is passed through the needle. If the outside-in technique is to be used, foraminoplasty is performed with sequential hand reamers starting from $4 \mathrm{~mm}$ to $9 \mathrm{~mm}$ on the guidewire (Figure 3). Proper caution must be taken not to advance the tip of the hand reamers beyond the medial pedicular line in the AP image in order to prevent possible nerve

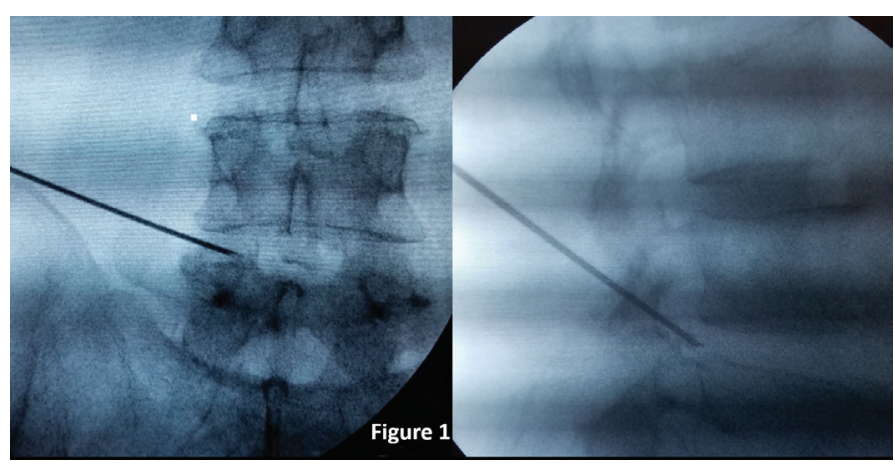

Figure 1. If the needle is in the medial pedicular line in the anteroposterior image and at the level of the posterior vertebra in the lateral image at the same time, it means that needle is in the ideal position

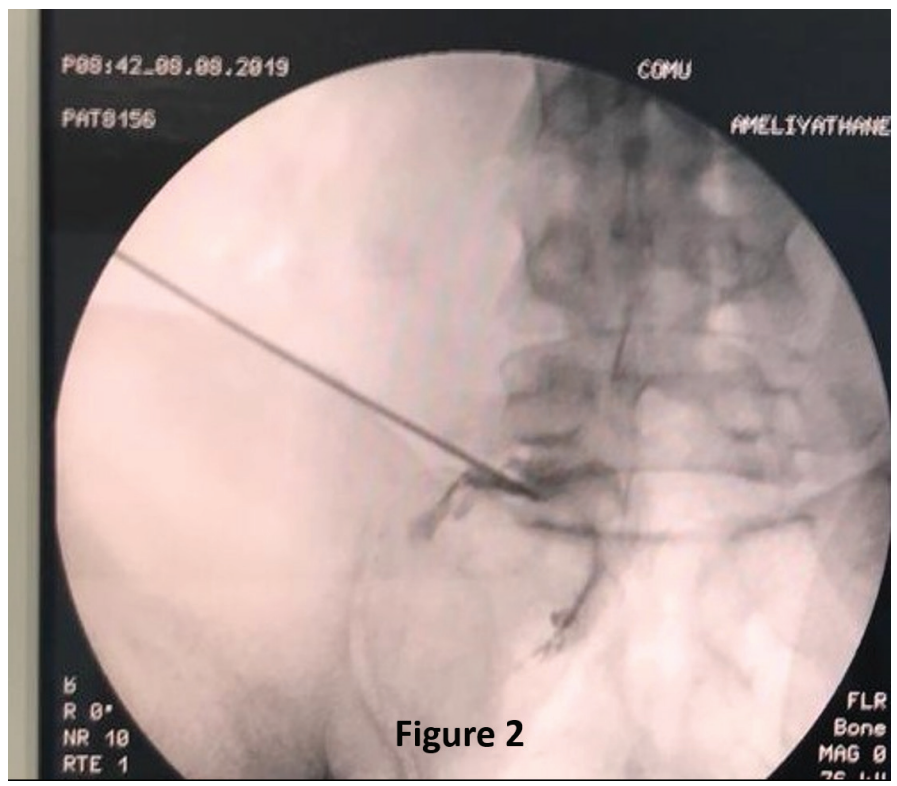

Figure 2. The location of the nerve roots and the safe triangle of Kambin where the drug will spread in the epidural space are confirmed with the injection of the radiopaque 


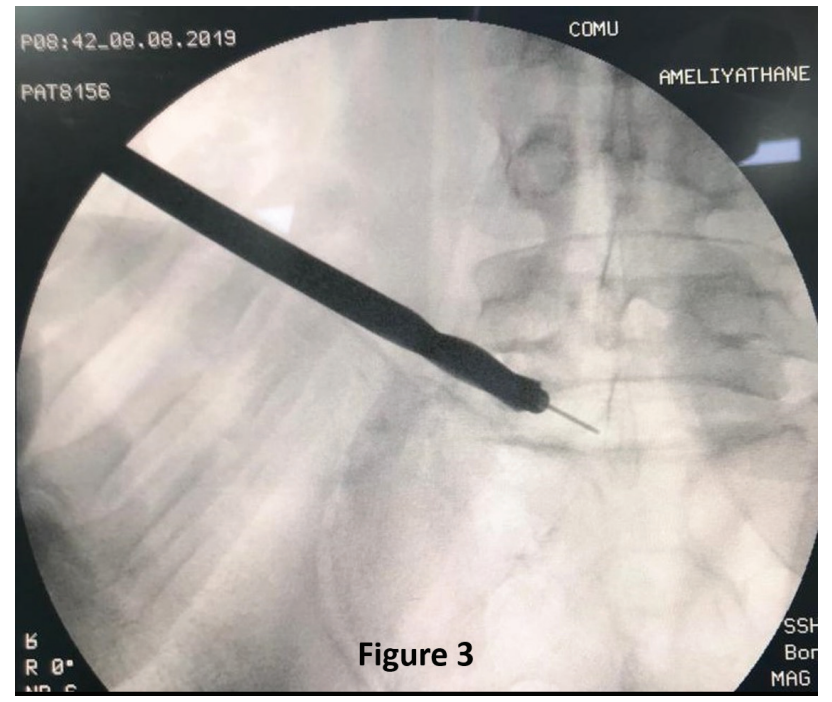

Figure 3. If outside-in technique is used, foraminoplasty is performed with sequential hand reamers starting from $4 \mathrm{~mm}$ to $9 \mathrm{~mm}$ on the guidewire

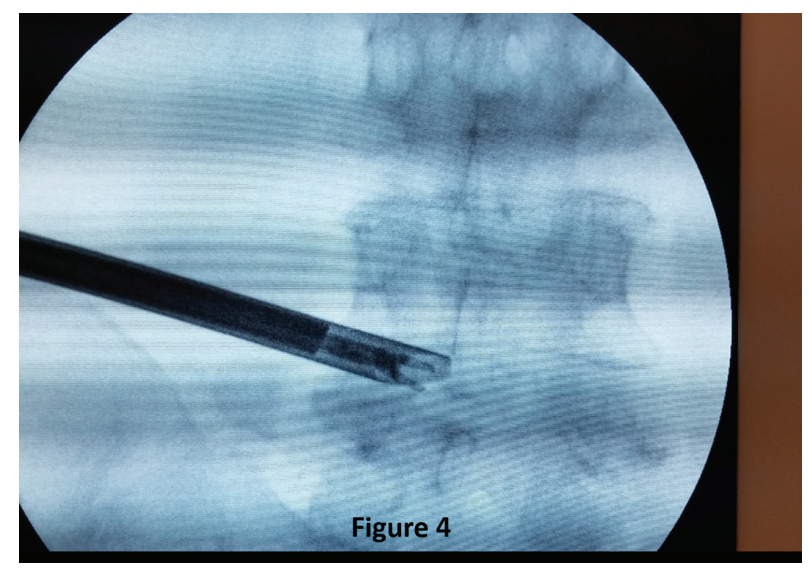

Figure 4. The obturator is removed from the working cannula and a $25^{\circ}$ endoscope is inserted into the working cannula to perform a discectomy using endoscopic forceps and other handpieces

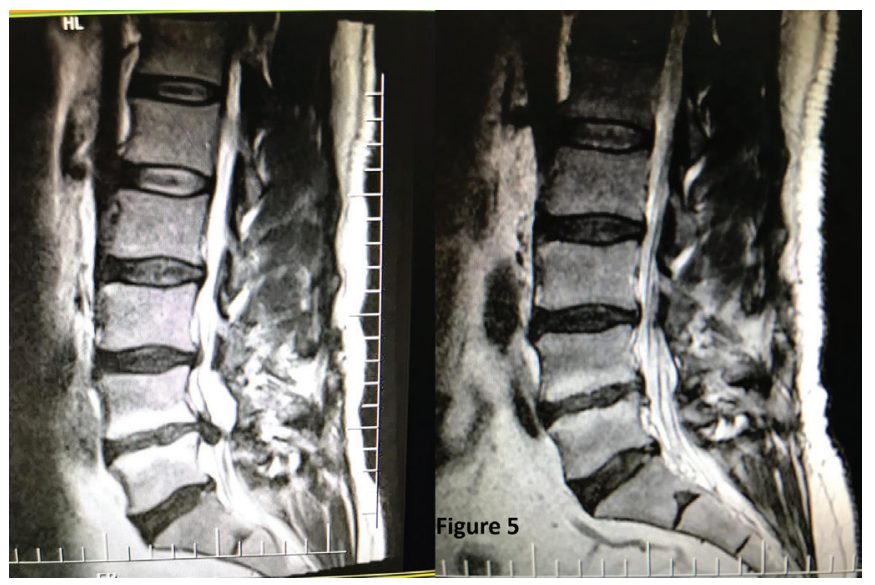

Figure 5. Preoperative and third-month follow-up magnetic resonance imaging of a 46-year-old male patient suffering from recurrent and down-migrated lumbar disc herniation at the L4-5 level, who we successfully treated with transforaminal percutaneous endoscopic lumbar discectomy injury. The obturator is then advanced over the guidewire. If the inside-out technique is to be used, the obturator is hammered into the disc on the guidewire. If the outside-in technique is to be used, the obturator is advanced to the location of the fragment. The cannula, which is $8 \mathrm{~mm}$ in diameter, is placed over the obturator with rotating movements. It should be noted that the opening of the angled working cannula faces dorsally in the epidural space. The obturator is removed from the working cannula and a $25^{\circ}$ endoscope is inserted into the working cannula to perform discectomy by using endoscopic forceps and other handpieces (Figure 4). When the inside-out technique is used, we used the half and half technique, as described by Lee et al. ${ }^{(20)}$. In this technique, half of the working cannula is placed in the ventral of the posterior line of the vertebral body (disc space), and the other half is placed dorsally in the epidural space.

\section{RESULTS}

The mean preoperative VAS score was 9.4 \pm 1.8 (range=8-10) and the mean early postoperative VAS score was $1.85 \pm 1.2$ (range=0-6). In our series, there was no $\mathrm{LDH}$ that we could not excise with transforaminal PELD. We confirmed the early postoperative decompression using axial and sagittal T2 MR images. During follow-up, recurrent LDH was seen in two patients. One patient developed epidural fibrosis. He was treated with sacral endoscopic lumbar neurolysis. The mean VAS scores were found to be $1.8 \pm 1.69$ at the third-month follow-up. At the last follow-up, $80 \%$ of the patients stated that they recovered completely and $85 \%$ stated that they could have the same surgery again. There was a significant difference between the preoperative VAS scores and the VAS scores in the early postoperative and third-month follow-up $(p<0.001)$. There was no significant difference between early postoperative VAS scores and the third month follow-up VAS scores $(p=0.9)$.

\section{DISCUSSION}

Percutaneous endoscopic disc surgery was modified by many innovative surgeons after the description of Kambin and Gellman ${ }^{(12,16)}$. Some of these modifications were Kambin et al. ${ }^{(17)}$ arthroscopic microdiscectomy, Yeung ${ }^{(39-41)}$ selective endoscopic discectomy, and Mayer and Brock ${ }^{(25,26)}$ PELD. In PELD, the preservation of central disc structures is very important for preventing future disc height reduction, disc degeneration, spinal instability, and postoperative low back pain. Therefore, changing the central disc decompression concept to targeted fragmentectomy was a significant innovation in the history of PELD technique(10,11,29). With the advancement of this technique, the skin entry point became more lateral $(10-14 \mathrm{~cm}$ from the midline) and the diameter of the working cannulas were enlarged to $7-8 \mathrm{~cm}$. As a result, complete removal of the herniated fragments became more feasible with the use of larger size endoscopic forceps and tools ${ }^{(12,28,29,35)}$. Due to these recent advancements in PELD techniques, there was no LDH that 
we could not excise with transforaminal PELD in our series. One common problem of PELD surgeries is the migration of herniated fragments. If the herniated fragment breaches the posterior longitudinal ligament (PLL) and moves into the epidural space, it migrates up or down route in $35 \%-72 \%$ of the cases ${ }^{(3,7,8,19,37)}$. Although there is a debate about in which direction it moves more commonly, most surgeons believe that down migration occurs more frequently ${ }^{(8,19,37)}$. Severely migrated fragments are generally placed under the pars interarticularis and medial to the pedicle. Therefore, open removal of these fragments requires extensive removal of the bone, which may result in postoperative instability $(8,24,27,32)$. Migrated fragments usually lie laterally away from the midline because of PLL attachments and midline septum. The peridural membrane also limits its passage to the midline. For these reasons, transforaminal access is a viable surgical option for migrated herniations ${ }^{(8,37)}$. Up-migrated herniations and sequestrations are more commonly seen in elderly patients who may likely have comorbidities such as cardiac disorders, hypertension, or diabetes. Because general anesthesia and open surgery may be risky, PELD with continuous sedation has remarkable advantages over open surgery for these patients ${ }^{(1,2,8)}$. In our series, there were only two patients with a migrated disc herniation who we treated successfully with transforaminal PELD. In one of these patients, LDH was a recurrent disc herniation which had been previously treated with an open microdiscectomy (Figure 5). One of these down migrated LDHs was at the L5-S1 level and required a foraminoplasty. Successful performance of an L5-S1 transforaminal PELD in patients with a high iliac crest can be challenging. Due to the oblique trajectory created by the iliac crest and narrow foraminal area, L5-S1 transforaminal PELD is a demanding procedure, which is hindered by the $L 5$ transverse process, the hypertrophic L5-S1 facet joint, and the sacral ala ${ }^{(9)}$. In the study conducted by Choi et al.(4) in which they retrospectively evaluated 100 patients who underwent transforaminal PELD for the L5-S1 level, they concluded that if the height of the iliac crest was located below the mid pedicle of the $L 5$, a conventional posterolateral approach could be performed without difficulty. However, if the height of the iliac crest was above the mid pedicle of the $L 5$, an appropriate working channel location sometimes required foraminal widening to remove the herniated mass. Foraminoplasty was particularly required in cases where the height of the iliac crest was above the L4-5 disc space, and/ or an android pelvis and/or central disc herniation was present. Due to these difficulties, half of the cases in which we performed PELD in the L5-S1 level required foraminoplasty ${ }^{(4,9)}$. A limitation of our study was the small sample size that was evaluated using transforaminal PELD. However, the validity of this approach has already been shown in the literature with larger series of patients in recent years ${ }^{(4,5,12,20-22,25,26,35,36,39-41)}$. In conclusion, the transforaminal PELD technique, which has evolved considerably in recent years, can be used to remove intra-canal, migrated, foraminal/extraforaminal, large, and recurrent disc herniations, under local and sedoanelgesia. It offers several advantages over an open surgical approach including the preservation of posterior ligamentous and bony structures, and less postoperative instability, facet arthropathy, disc space narrowing, and epidural scarring.

\section{CONCLUSION}

PELD under local and sedoanalgesia is an alternative method to classical microdiscectomy in patients with lumbar disc hernia. It is a crucial advantage that it does not require general anesthesia and that patients can provide feedback during surgery. In the early postoperative period, it is possible to evaluate whether the decompression is sufficient with the straight leg raising test before the patient leaves the operating room. Because the procedure does not require nerve manipulation and normal anatomical structures are not damaged, the patient feels less pain in the early postoperative period, can be discharged on the same day, and can return to their daily activities and work life more quickly.

\section{Ethics}

Ethics Committee Approval: Retrospective study.

Informed Consent: Retrospective study.

Peer-review: Internally peer-reviewed.

Financial Disclosure: The author declared that this study received no financial support.

\section{REFERENCES}

1. Akagi S, Saito T, Kato I, Sasai K, Ogawa R. Clinical and pathologic characteristics of lumbar disk herniation in the elderly. Orthopedics 2000;23:445-8.

2. An HS, Vaccaro A, Simeone FA, Balderston RA, O'Neill D. Herniated lumbar disc in patients over the age of fifty. J Spinal Disord 1990;3:143-6.

3. Brock M, Patt $S$, Mayer HM. The form and structure of the extruded disc. Spine 1992;17:1457-61.

4. Choi G, Lee SH, Lokhande P, Kong B], Shim CS, Jung B, et al Percutaneous endoscopic approach for highly migrated intracanal disc herniations by foraminoplastic technique using rigid working channel endoscope. Spine 2008;15:E508-15.

5. Choi G, Prada N, Modi HN, Vasavada NB, Kim IS, Lee SH. Percutaneous endoscopic lumbar herniectomy for high-grade down-migrated L4L5 disc through an L5-S1 interlaminar approach: a technical note. Minim Invasive Neurosurg 2010;53:147-52.

6. Cooper RG, Mitchell WS, Illingworth KJ, Forbes WS, Gillespie JE, Jayson MI. The role of epidural fibrosis and defective fibrinolysis in the persistence of postlaminectomy back pain. Spine 1991;16:1044-8.

7. Ebeling $\mathrm{U}$, Reulen $\mathrm{HJ}$. Are there typical localisations of lumbar disc herniations? A prospective study. Acta Neurochir (Wien) 1992;117:143-8.

8. Eun SS, Lee SH, Erken HY. Transforaminal Percutaneous Endoscopic Lumbar Diskectomy for Downmigrated Disk Herniations: Lever-Up, Rotate, and Tilt Technique. J Neurol Surg A Cent Eur Neurosurg 2018;79:163-8.

9. Eun SS, Lee SH, Liu WC, Erken HY. A novel preoperative trajectory evaluation method for L5-S1 transforaminal percutaneous endoscopic lumbar discectomy. Spine J 2018;18:1286-91.

10. Faulhauer K, Manicke C. Fragment excision versus conventional disc removal in the microsurgical treatment of herniated lumbar disc. Acta Neurochir (Wien) 1995;133:107-11. 
11. Goel VK, Nishiyama K, Weinstein JN, Liu YK. Mechanical properties of lumbar spinal motion segments as affected by partial disc removal. Spine 1986; 11:1008-12.

12. Hijikata S, Yamagishi M, Nakayma T. Percutaneous discectomy: a new treatment method for lumbar disc herniation. J Tokyo Den-ryoku Hosp 1975;5:39-44.

13. Kambin P. Posterolateral percutaneous lumbar discectomy and decompression. In: Kambin P, (Ed.). Arthroscopic Microdiscectomy: Minimal Intervention in Spinal Surgery. Urban \& Schwarzenberg, Baltimore, MD 1991;pp:67-100.

14. Kambin P, Casey K, O'Brien E, Zhou L. Transforaminal arthroscopic decompression of lateral recess stenosis. J Neurosurg 1996;84:462-7.

15. Kambin P, Cohen LF, Brooks M, Schaffer JL. Development of degenerative spondylosis of the lumbar spine after partial discectomy. Comparison of laminotomy, discectomy, and posterolateral discectomy. Spine 1995;20:599-607.

16. Kambin P, Gellman H. Percutaneous lateral discectomy of the lumbar spine: a preliminary report. Clin Ortho 1983;174:127-32.

17. Kambin P, O'Brien E, Zhou L, Schaffer JL. Arthroscopic microdiscectomy and selective fragmentectomy. Clin Orthop Relat Res 1998;347:150-67.

18. Kambin P, Sampson S. Posterolateral percutaneous suction-excision of herniated lumbar intervertebral discs. Report of interim results. Clin Orthop Relat Res 1986;207:37-43.

19. Kuzeyli K, Cakir E, Usul H, Baykal S, Yazar U, Karaarslan G, et al. Posterior epidural migration of lumbar disc fragments: report of three cases. Spine 2003;28:E64-E7.

20. Lee S, Kim SK, Lee SH, Kim WJ, Choi WC, Choi G, et al. Percutaneous endoscopic lumbar discectomy for migrated disc herniation: classification of disc migration and surgical approaches. Eur Spine J 2007; 16:431-7.

21. Lee SH, Kang BU, Ahn Y, Choi G, Choi YG, Ahn KU, et al. Operative failure of percutaneous endoscopic lumbar discectomy: a radiologic analysis of 55 cases. Spine 2006;31:E285-E90.

22. Lee SH, Kang HS, Choi G, Kong BJ, Ahn Y, Kim JS, et al. Foraminoplastic ventral epidural approach for removal of extruded herniated fragment at the L5-S1 level. Neurol Med Chir (Tokyo) 2010;50:1074-8.

23. Lee SH, Kang HS. Percutaneous endoscopic laser annuloplasty for discogenic low back pain. World Neurosurg 2010;73:198-206; discussion e33.

24. Macnab I. Negative disc exploration. An analysis of the causes of nerve-root involvement in sixty-eight patients. J Bone Joint Surg Am 1971;53:891-903.

25. Mayer HM, Brock M. Percutaneous endoscopic discectomy: surgical technique and preliminary results compared to microsurgical discectomy. J Neurosurg 1993;78:216-25.

26. Mayer HM, Brock M. Percutaneous endoscopic lumbar discectomy (PELD). Neurosurg Rev 1993;16:115-20.
27. McCulloch JA, Young PH. Microsurgery for lumbar disc herniation. In: McCulloch JA, Young PH, (Eds.). Essentials of Spinal Microsurgery. Lippincott-Raven, Philadelphia 1998;pp:329-82.

28. Mirkovic SR, Schwartz DG, Glazier KD. Anatomic considerations in lumbar posterolateral percutaneous procedures. Spine 1995;20:1965-71.

29. Mochida J, Nishimura K, Nomura T, Toh E, Chiba M. The importance of preserving disc structure in surgical approaches to lumbar disc herniation. Spine 1996;21:1556-63.

30. Mochida J, Toh E, Nomura T, Nishimura K. Risks and benefits of percutaneous nucleotomy for lumbar disc herniation. A 10-year longitudinal study. J Bone Joint Surg Br 2001;83:501-5.

31. Natarajan RN, Andersson GB, Patwardhan AG, Andriacchi TP. Study on effect of graded facetectomy on change in lumbar motion segment torsional flexibility using three-dimensional continuum contact representation for facet joints. J Biomech Eng 1999;121:215-21.

32. Osman SG, Nibu K, Panjabi MM, Marsolais EB, Chaudhary R. Transforaminal and posterior decompressions of the lumbar spine. A comparative study of stability and intervertebral foramen area. Spine 1997;22:1690-5.

33. Parke WW. The significance of venous return impairment in ischemic radiculopathy and myelopathy. Orthop Clin North Am 1991;22:213-21.

34. Ross JS, Robertson JT, Frederickson RC, Petrie JL, Obuchowski N, Modic $\mathrm{MT}$, et al. Association between peridural scar and recurrent radicular pain after lumbar discectomy: magnetic resonance evaluation. ADCON-L European Study Group. Neurosurgery 1996;38:855-61.

35. Ruetten S, Komp M, Godolias G. An extreme lateral access for the surgery of lumbar disc herniations inside the spinal canal using the full-endoscopic uniportal transforaminal approach-technique and prospective results of 463 patients. Spine 2005;30:2570-8.

36. Schaffer JL, Kambin P. Percutaneous posterolateral lumbar discectomy and decompression with a 6.9-millimeter cannula. Analysis of operative failures and complications. J Bone Joint Surg Am 1991;73:822-31.

37. Schellinger D, Manz HJ, Vidic B, Patronas NJ, Deveikis JP, Muraki AS, et al. Disk fragment migration. Radiology 1990;175:831-6.

38. Weber BR, Grob D, Dvorak J, Müntener M. Posterior surgical approach to the lumbar spine and its effect on the multifidus muscle. Spine 1997;22:1765-72.

39. Yeung AT. Minimally invasive disc surgery with the Yeung endoscopic spine system (YESS). Surg Technol Int 2000;8: 267-277.

40. Yeung AT. The evolution of percutaneous spinal endoscopy and discectomy: state of the art. Mt Sinai J Med 2000;67:327-32.

41. Yeung AT, Tsou PM. Posterolateral endoscopic excision for lumbar disc herniation: surgical technique, outcome, and complications in 307 consecutive cases. Spine 2002;27:722-31.

42. Zander T, Rohlmann A, Klockner C, Bergmann G. Influence of graded facetectomy and laminectomy on spinal biomechanics. Eur Spine J 2003; 12:427-34. 